Mexican Journal of Biotechnology 2021, 6(4):1-16

Journal homepage:www.mexjbiotechnol.com

\title{
Azospirillum brasilense stimulate the growth in Arabidopsis thaliana through the target of rapamycin protein
}

\section{Azospirillum brasilense estimula el crecimiento en Arabidopsis thaliana a través de la proteína diana de rapamicina}

Manuel Méndez-Gómez, Elda Castro-Mercado, Ernesto García-Pineda*

Instituto de Investigaciones Químico Biológicas, Edif. A1', Ciudad Universitaria, Universidad Michoacana de San Nicolás de Hidalgo, Morelia, CP 58040. Michoacán, Mexico.

*Corresponding author

E-mail address: egpineda@umich.mx (E. García-Pineda). ORCID: 0000-00024739-7741

Article history:

Received: 18 June 2021 / Received in revised form: 26 July 2021 / Accepted: / 14 August 2021 / Published online: 1 October 2021.

https://doi.org/10.29267/mxib.2021.6.4.1

\begin{abstract}
Azospirillum spp., one of the best studied genus of plant growth promoting rhizobacteria. These rhizobacteria are able to colonize hundreds of plant species and improve their growth, development and productivity. The target of rapamycin (TOR) protein is a central component of the TOR signaling pathway, which regulates cell growth and metabolism in response to environment cues in eukaryotes. In this study, the TOR function was analyzed in Arabidopsis thaliana L. plants inoculated with the rhizobacteria Azospirillum brasilense. Arabidopsis seedlings tor-es, which express an interference RNA in presence of estradiol and decrease TOR expression, showed an inhibition in the growth and lateral root formation, with or without $1 \times 10^{2} \mathrm{CFU} / \mathrm{mL}$ of the inoculum. In addition, a morphological analysis of the root showed an inhibition in the root hair formation. The results suggest that $A$. brasilense controls $A$. thaliana growth through TOR signaling pathway.
\end{abstract}

Keywords: Plant growth, rhizobacteria, lateral root, estradiol. 


\section{RESUMEN}

Azospirillum spp., es uno de los géneros mejor estudiados de rizobacterias que promueven el crecimiento vegetal. Estas rizobacterias son capaces de colonizar cientos de especies de plantas, y mejorar su crecimiento, su desarrollo, y su productividad. La proteína blanco de la rapamicina (TOR; Target Of Rapamycin) es un componente central de la vía de señalización TOR, la cual regula el crecimiento celular y el metabolismo en respuesta a señales del ambiente en eucariotes. En este estudio se analizó la función de TOR en plantas de Arabidopsis thaliana L. inoculadas con la rizobacteria Azospirillum brasilense. Plántulas de Arabidopsis tor-es, las cuales expresan un ARN de interferencia en presencia de estradiol y disminuye la expresión de TOR, mostraron una inhibición en el crecimiento, y en la formación de raíces laterales en ausencia o en presencia de $1 \times 10^{2} \mathrm{UFC} / \mathrm{mL}$ del inóculo. En un análisis morfológico de la raíz se observó además una inhibición en la formación de los pelos de la raíz. Los resultados sugieren que $A$. brasilense regula el crecimiento de $A$. thaliana a través de la vía de señalización TOR.

Palabras clave: Crecimiento vegetal, rizobacterias, raíz lateral, estradiol.

\section{INTRODUCCIÓN}

Las rizobacterias que promueven el crecimiento vegetal (PGPR; Plant Growth Promoting Rhizobacteria) son una categoría específica de microorganismos que promueven el crecimiento vegetal a través de su interacción con la raíz (Tabassum et al., 2017; Zhou \& Huang, 2015). Las PGPR usan varios mecanismos para incrementar el crecimiento vegetal, asegurando la disponibilidad y adquisición de nutrientes para la planta, y actúan como agentes de biocontrol previniendo a la planta de ser infectada por diferentes patógenos como virus, hongos, insectos y bacterias (Khan \& Bano, 2016; Jha \& Saraf, 2015). Estas bacterias juegan un papel esencial en mejorar la eficiencia de los fertilizantes, la tolerancia a estrés por salinidad y sequía en las plantas, y la bioremediación de suelos contaminados por metales pesados (Tiwari et al., 2015; Vishan et al., 2019). Por estas características se han considerado como una alternativa para mantener el ambiente libre de la adición de fertilizantes químicos. Actualmente, la interacción de las PGPR con las plantas se explora considerándose como un metaorganismo (rizobacteria/planta), el efecto del microorganismo solo o en consorcio, la función de los exudados de la raíz y la biología molecular de ambos (Thijs et al., 2016).

El género Azospirillum pertenece a un grupo de PGPR ampliamente estudiado. Si bien el beneficio más relevante sobre las plantas es su capacidad para fijar nitrógeno, poseen otras propiedades que promueven el crecimiento vegetal. Una de ellas es su capacidad para producir reguladores del crecimiento vegetal (fitohormonas) como las auxinas (Spaepen \& Vanderleyden 2015), citocininas (Tien et al., 1979), giberelinas (Bottini et al., 1989), ácido abscísico (Cohen et al., 2008), etileno (Strzelczyk et al., 1994), y ácido salicílico (Sahoo et al., 2014). Estas 
fitohormonas afectan el crecimiento de la raíz derivando en un mejoramiento de la toma de nutrientes por la planta (Ardakani \& Mafakheri 2011).

Algunas cepas de Azospirillum pueden solubilizar fósforo inorgánico, haciéndolo más disponible para las plantas e incrementado su rendimiento (Turan et al., 2012). Además, mitigan el estrés abiótico provocado por la salinidad y la sequía (Creus et al., 2004; Kim et al., 2012). Otra importante característica de Azospirillum está relacionada con el control biológico de patógenos, a través de la síntesis de sideróforos, los cuáles limitan la disponibilidad de hierro para los fitopatógenos, y la síntesis de metabolitos secundarios. Estos metabolitos incrementan la resistencia a infecciones a través de un mecanismo conocido como resistencia sistémica inducida (Bashan \& de-Bashan 2002; Khan et al., 2002; Romero et al., 2003; Tortora et al., 2011; Sudha \& Ravishankar 2002; van Loon \& Bakker 2005).

La proteína cinasa TOR es reconocida como un regulador de desarrollo clave en plantas y animales (Burkart \& Brandizz 2021). Los eucariontes poseen una TOR cinasa funcional, la cual integra señales de nutrientes y del ambiente para regular el crecimiento y el desarrollo. Esto es particularmente importante en plantas porque como organismos sésiles deben percibir y responder a señales externas para coordinar apropiadamente el crecimiento multicelular. Así, la investigación sobre la función de TOR es esencial para comprender cómo se controla el desarrollo vegetal, en el contexto de la interacción planta-rizobacteria. Nutrientes y factores de crecimiento activan a TOR, mientras que la privación de energía, la inanición y el estrés la inactivan (Dobrenel et al., 2016). Existe un solo gen TOR en Arabidopsis, en la mayoría de los animales, y en los humanos (Xiong \& Sheen, 2014). Este gen codifica para una serina/treonina cinasa altamente conservada (Menand et al., 2002; Zoncu et al., 2011). Uno de los blancos de fosforilación de TOR es la proteína ribosomal S6 KINASE (S6K), la cual promueve el desarrollo del cloroplasto y el crecimiento vegetal (Shi et al., 2018). La proteína TOR se expresa en el meristemo apical de la raíz y del follaje (Menand et al., 2002). También se ha reportado como regulador del tamaño celular, porque plantas inducibles con estradiol para silenciar TOR en Arabidopsis mostraron una reducción en la biomasa, en el tamaño celular y en el tamaño de la hoja (Deprost et al., 2007; Xiong \& Sheen, 2012). Actualmente se desconoce si esta proteína está involucrada en el crecimiento vegetal estimulado por rizobacterias. En este estudio se reporta la función de la proteína TOR en $A$. thaliana durante la estimulación del crecimiento por $A$. brasilense.

\section{MATERIAL Y MÉTODOS}

\subsection{Material biológico}

En este estudio se utilizaron plantas de tipo silvestre de $A$. thaliana Col0 y las mutantes tor-es, la cual está condicionada en la expresión de TOR, a través de la adición de estradiol al medio de crecimiento (Xiong et al., 2013), s6k1-1, 2-1 y 2-2. 
Para su crecimiento, las semillas de $A$. thaliana se desinfectaron con etanol al $95 \%$ (vol/vol) durante $5 \mathrm{~min}$, y $20 \%$ de cloro comercial durante 5 min, seguido por cinco lavados con agua destilada estéril. Las semillas se almacenaron a $4{ }^{\circ} \mathrm{C}$ durante 2 días antes de la germinación. Las semillas se germinaron y crecieron en cajas Petri con agar conteniendo medio Murashige y Skoog (MS) (Murashige \& Skoog, 1962) al $0.2 \mathrm{X}$, a pH 7 (0.9 g/L de sales MS, $6 \mathrm{~g} / \mathrm{L}$ de sacarosa y $10 \mathrm{~g} / \mathrm{L}$ de Agar Plant TC (PhytoTechnology Laboratories, St, Lenexa, KS, USA). Las plantas se colocaron verticalmente en una cámara de crecimiento (Percival Scientific AR-95L) a $22{ }^{\circ} \mathrm{C}$ con un fotoperiodo de $16 \mathrm{~h}$ luz/8 h oscuridad (intensidad de la luz 100

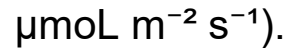

La cepa silvestre de A. brasilense Sp245 fue donada por la Dra. Gladys Alexandre, de la Universidad de Tennessee, USA. La bacteria se cultivó en medio líquido LB, a pH de 7.0 (peptona $10 \mathrm{~g} / \mathrm{L}$, extracto de levadura $5 \mathrm{~g} / \mathrm{L}, \mathrm{NaCl} 5 \mathrm{~g} / \mathrm{L}$, suplementado con $\mathrm{MgSO}_{4} 0.30 \mathrm{~g} / \mathrm{L}$ y $\mathrm{CaCl}_{2} 0.277 \mathrm{~g} / \mathrm{L}$; para medio sólido se agregaron $15 \mathrm{~g} / \mathrm{L}$ de agar).

Para preparar el inóculo, se aplicó el procedimiento reportado por Spaepen et al. (2014). El cultivo creció durante $20 \mathrm{~h}$ (crecimiento exponencial) a $27^{\circ} \mathrm{C}$, en agitación a $100 \mathrm{rpm}$. Se lavó dos veces en $\mathrm{NaCl}$ al $0.9 \%$ por centrifugación (4300 x $\mathrm{g}, 10 \mathrm{~min}, 4^{\circ} \mathrm{C}$ ) y se resuspendió en $\mathrm{MgSO}_{4} 0.01 \mathrm{M}$. Se realizaron diluciones secuenciales para obtener la concentración final deseada en Unidades Formadoras de Colonias (UFC) por mililitro.

\subsection{Tratamiento de las semillas}

Cuatro días después de la germinación las plántulas se trasplantaron asépticamente en cajas Petri conteniendo medio Murashige \& Skoog (MS) 0.2X, $\mathrm{pH}$ 7.0. La bacteria ( $\left.10 \mu \mathrm{L}, 10^{2} \mathrm{UFC} / \mathrm{mL}\right)$ se colocó formando una línea horizontal 1 $\mathrm{cm}$ debajo del follaje. Las cajas se sellaron con plástico adherente y se incubaron verticalmente en una cámara de crecimiento, previamente descrita.

\subsection{Análisis del crecimiento vegetal}

Los parámetros de crecimiento se analizaron 6 días después del trasplante. El peso fresco de las plántulas se determinó con una balanza analítica (Ohaus V14130 Voyager). El crecimiento de la raíz primaria se midió con una regla. El número de raíces laterales se determinó usando un microscopio estereoscópico (Leica MZ6). La densidad de raíces laterales (DRL) se obtuvo dividiendo el número de raíces laterales entre la longitud de la raíz primaria. Para analizar el meristemo de la raíz primaria, la raíz se clarificó (Malamy \& Benfey 1997) y se analizó usando un microscopio Nomarski (Leica DFC450C). La longitud del meristemo se consideró como la distancia entre el centro quiescente y el principio de la zona de elongación, y se obtuvo de imágenes analizadas con el programa ImageJ. 


\subsection{Análisis histoquímico}

La división celular se analizó con el marcador de división celular CYCB1;1::GUS. Para el análisis se utilizaron líneas transgénicas que expresan el gen reportero uidA (GUS; $\beta$-glucuronidasa), unido a la región promotora del gen CYCB1;1. Las plántulas se tiñeron con X-Gluc (5-bromo-4-chloro-3-indolyl $\beta$-D-glucuronide) al $0.1 \%$, disuelto en amortiguador de fosfato $\left(\mathrm{NaH}_{2} \mathrm{PO}_{4}\right.$ y $\left.\mathrm{Na}_{2} \mathrm{HPO}_{4}, 0.1 \mathrm{M}, \mathrm{pH} 7\right)$, ferrocianuro de potasio $2 \mathrm{mM}$ y ferricianuro de potasio $2 \mathrm{mM}$, durante toda la noche a $37^{\circ} \mathrm{C}$. Las plántulas se clarificaron, se fijaron (Malamy y Benfey 1997) y se montaron en portaobejtos y se sellaron con barniz comercial. Se tomaron fotografías en un microscopio y se analizaron las imágenes.

\subsection{Análisis estadístico}

Todos los experimentos se repitieron al menos tres veces. Los datos se analizaron usando el programa STATISTICA versión 8.0.550. Se realizó análisis de multivariado seguido por análisis post-hoc (Tukey's HSD), para examinar diferencias entre grupos experimentales.

\section{RESULTADOS}

\subsection{Efecto de $A$. brasilense sobre el crecimiento de $A$. thaliana}

El análisis morfológico mostró una disminución del crecimiento en la raíz de las plántulas inoculadas, y un incremento en el número de raíces laterales (Fig. 1A). Cuantitativamente, la longitud de la raíz principal disminuyó aprox. $37 \%$, mientras que el número de raíces laterales se incrementó siete veces (Fig. 1B, C). El peso fresco del follaje se incrementó 1.5 veces, y el de la raíz 3.5 veces (Fig. 1 D, E). 


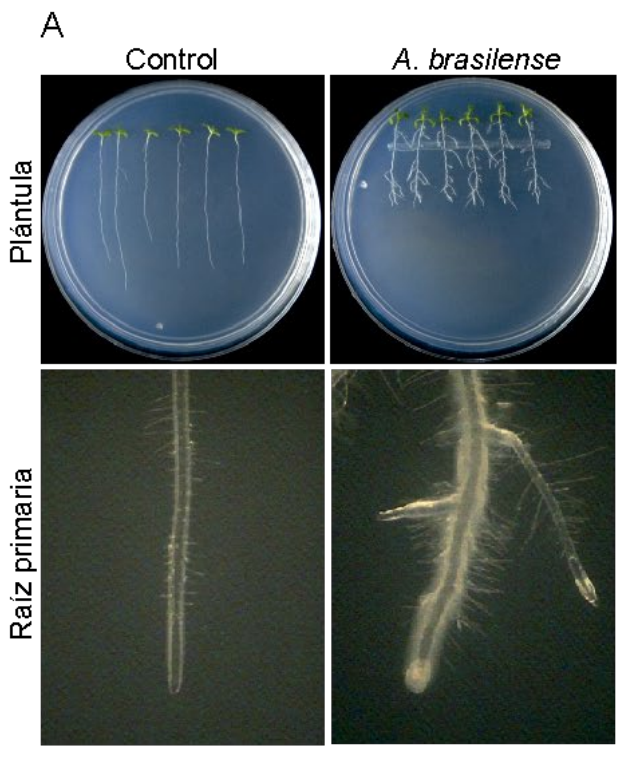

$\mathrm{B}$
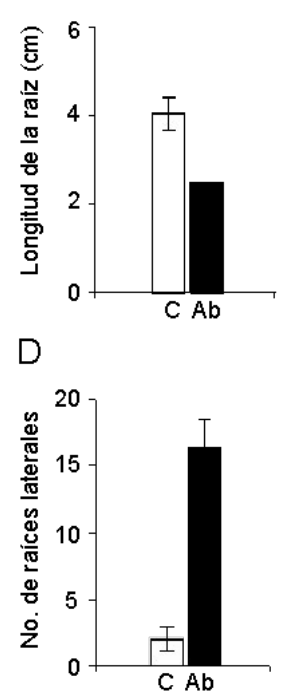

$\mathrm{C}$

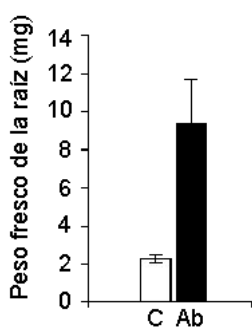

E

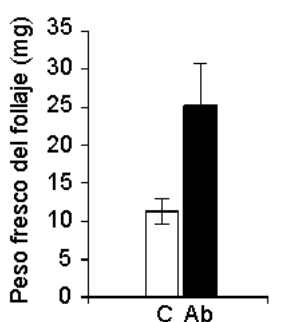

Fig. 1. Efecto de A. brasilense sobre el crecimiento de $A$. thaliana. A. Panel superior. Morfología de las plántulas. Panel inferior. Morfología de la raíz primaria. $\mathrm{B}-\mathrm{E}$. Análisis de parámetros de crecimiento. $\mathrm{C}=$ control; $\mathrm{Ab}=A$. brasilense; $\mathrm{N}=$ 30.

Fig. 1. Effect of $A$. brasilense on $A$. thaliana growth. A. Upper panel. Morphology of the seedlings. Lower panel. Morphology of the primary root. B-E. Analysis of the growth parameters. $\mathrm{C}=$ control; $\mathrm{Ab}=\mathrm{A}$. brasilense; $\mathrm{N}=30$.

\subsection{Efecto de la inoculación sobre la división celular en la raíz}

Se analizó el efecto de la inoculación $\left(1 \times 10^{2} \mathrm{UFC} / \mathrm{mL}\right)$ sobre la división celular en el meristemo de la raíz, utilizando el reportero CYCB1;1::GUS. La división celular disminuyó en la raíz principal, y aumentó en las raíces laterales (Fig. 2A). El número de células en división en el meristemo de la raíz principal disminuyó en aprox. 64\%, y la longitud del meristemo en un 22\% (Fig. 2B, C). 


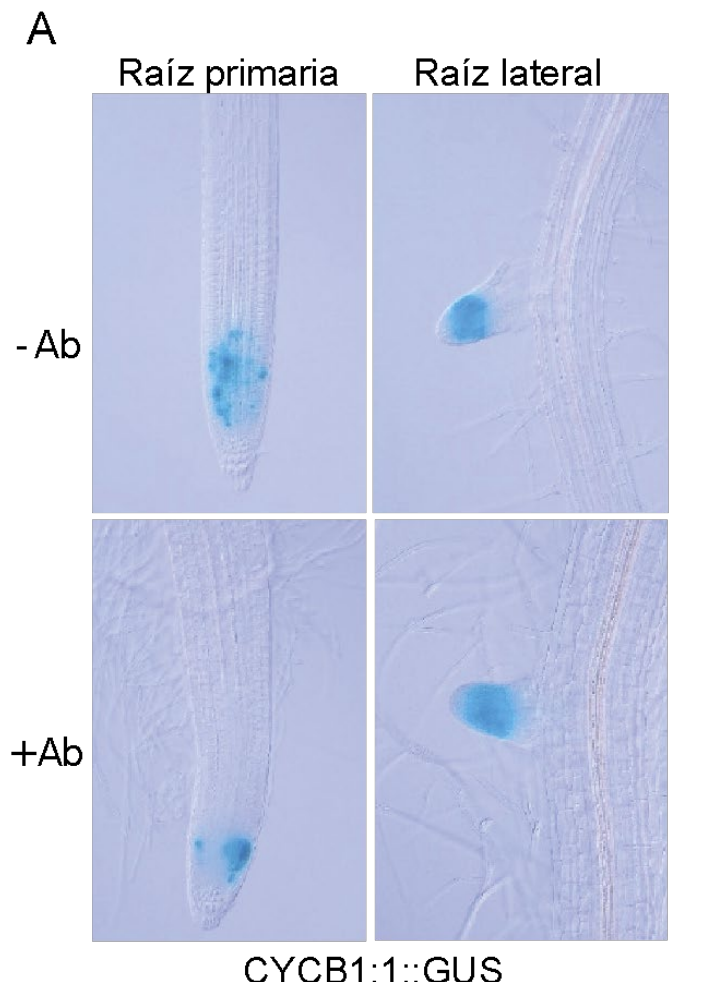

B
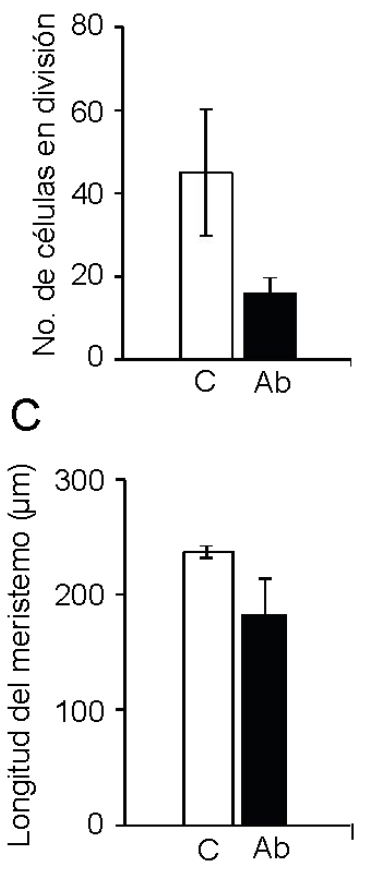

Fig. 2. Efecto de $A$. brasilense sobre la división celular en la raíz de $A$. thaliana. A. Expresión de ciclina en la raíz principal y en la raíz lateral. B. Número de células en división en la raíz principal. $\mathbf{C}$. Longitud del meristemo de la raíz principal. $\mathbf{C}=$ control; $\mathrm{Ab}=$ A. brasilense; $\mathrm{N}=30$.

Fig. 2. Effect of $A$. brasilense on the root cell division of $A$. thaliana. A. Cyclin expression in the primary and lateral root. B. Number of cells in division in the primary root. $\mathbf{C}$. Meristem length of the primary root. $\mathrm{C}=$ control; $\mathrm{Ab}=A$. brasilense; $\mathrm{N}=30$.

\subsection{La inhibición de TOR suprime la promoción del crecimiento por $A$. brasilense.}

Para analizar el papel de la proteína TOR durante la estimulación del crecimiento por la rizobacteria, se utilizaron plantas mutantes tor-es. Estas plantas están transformadas genéticamente con una construcción molecular que expresa un ARN de interferencia, cuya síntesis es inducida por la aplicación de estradiol. Cuando se sintetiza el ARN su secuencia de nucleótidos es complementaria a la secuencia del ARN mensajero de TOR, formándose una doble cadena que es degradada por la célula. De esta manera se disminuye la cantidad de esta proteína y se puede analizar su función. Las plántulas tor-es inoculadas $\left(1 \times 10^{2}\right.$ UFC/mL) en ausencia de estradiol mostraron una estimulación del crecimiento similar a las plántulas silvestres; pero cuando se adicionó estradiol $(0.07 \mu \mathrm{M})$ se 
suspendió el crecimiento de las plántulas en ausencia de la rizobacteria. Las características de promoción del crecimiento no se observaron en las plántulas inoculadas en presencia de estradiol (Fig. 3A). Cuantitativamente, la diferencia de crecimiento entre las plantas tratadas con estradiol no inoculadas o inoculadas fue de $75 \%$. La estimulación en la formación de raíces laterales también fue drásticamente inhibida por el estradiol (Fig. 3B, C).

A
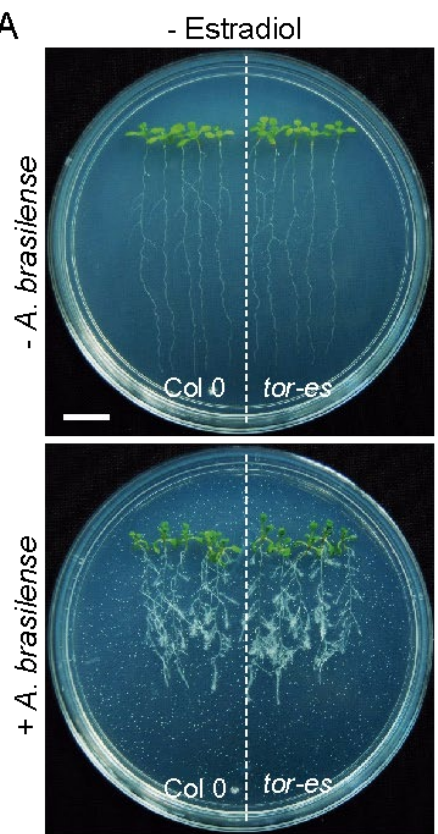

+ Estradiol
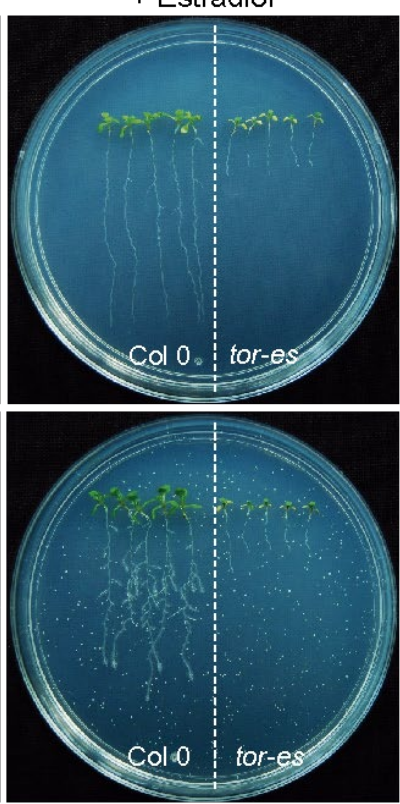

$B$

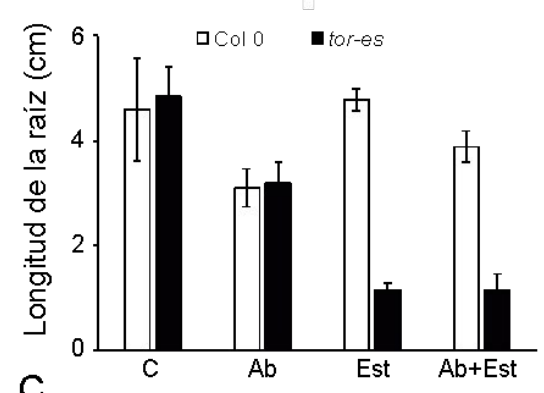

C

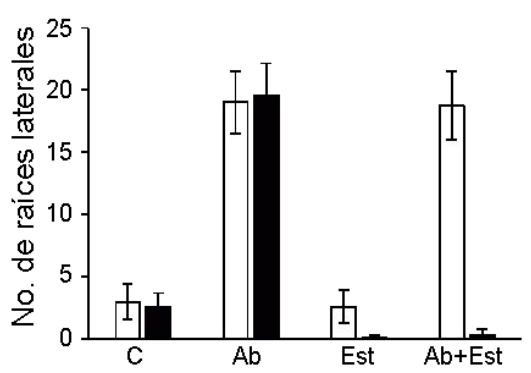

Fig. 3. Efecto de $A$. brasilense sobre sobre mutantes condicionales en la expresión de TOR. Semillas de $A$. thaliana se germinaron durante 4 días, y después crecidas en medio sin- o con estradiol durante 6 días. A. Morfología de las plántulas. B, C. Análisis de los parámetros morfológicos de la raíz. Barra de escala $=1 \mathrm{~cm}$. $C=$ control; $\mathrm{Ab}=$ A. brasilense; Est $=$ estradiol. $\mathrm{N}=30$.

Fig. 3. Effect of $A$. brasilense on the conditional mutants in TOR expression. Seeds of $A$. thaliana were germinated during 4 days and then grown in medium with or without estradiol by 6 days. A. Morphology of the seedlings. B, C. Analysis of the morphological parameters of the root. Scale bar $=1 \mathrm{~cm}$. $\mathrm{C}=$ control; $A b=A$. brasilense; Est $=$ estradiol. $\mathrm{N}=30$.

Un análisis más detallado sobre la morfología de la raíz primaria mostró que la formación de los pelos de la raíz también se inhibió en las plántulas tor-es inoculadas, y tratadas con estradiol (Fig. 4). 


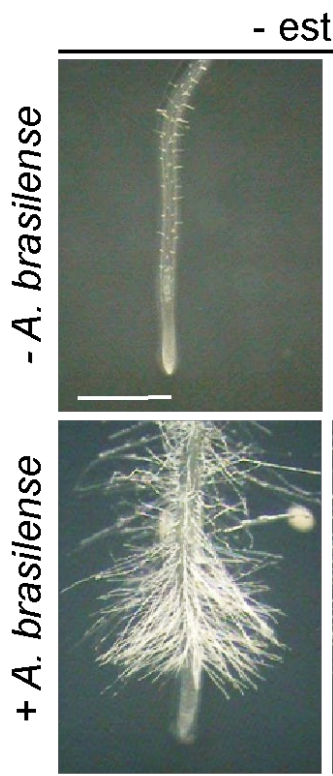

Col 0

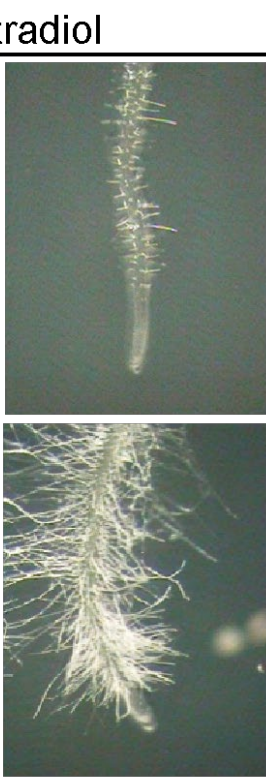

tor-es

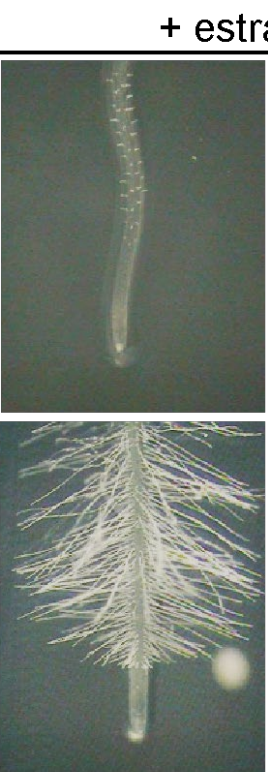

Col 0
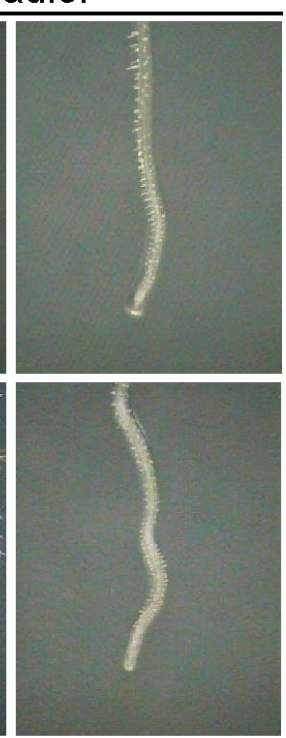

tor-es

Fig. 4. Efecto de $A$. brasilense sobre la morfología de la raíz de mutantes condicionales en la expresión de TOR. Barra de escala $=1 \mathrm{~mm} . \mathrm{N}=30$.

Fig. 4. Effect of $A$. brasilense on the root morphology of conditional mutants in TOR expression. Scale bar $=1 \mathrm{~mm}$. $\mathrm{N}=30$.

\subsection{Efecto de la inoculación sobre la proteína blanco de TOR S6K}

Cuando la proteína cinasa TOR está activa, fosforila a la proteína cinasa S6K, como parte importante de su mecanismo de acción para afectar el crecimiento celular. Para analizar el efecto de la inoculación sobre el papel de la proteína S6K, como parte de la ruta metabólica de TOR, se utilizaron plántulas de $A$. thaliana mutadas en diferentes alelos de S6K: $s 6 k 1-1, s 6 k 2-1$ y s6k2-2. La rizobacteria disminuyó el crecimiento de la raíz primaria, y estimuló la formación de raíces laterales en las diferentes plántulas mutantes de forma similar a las plántulas silvestres (Fig. 5A, B, C). 

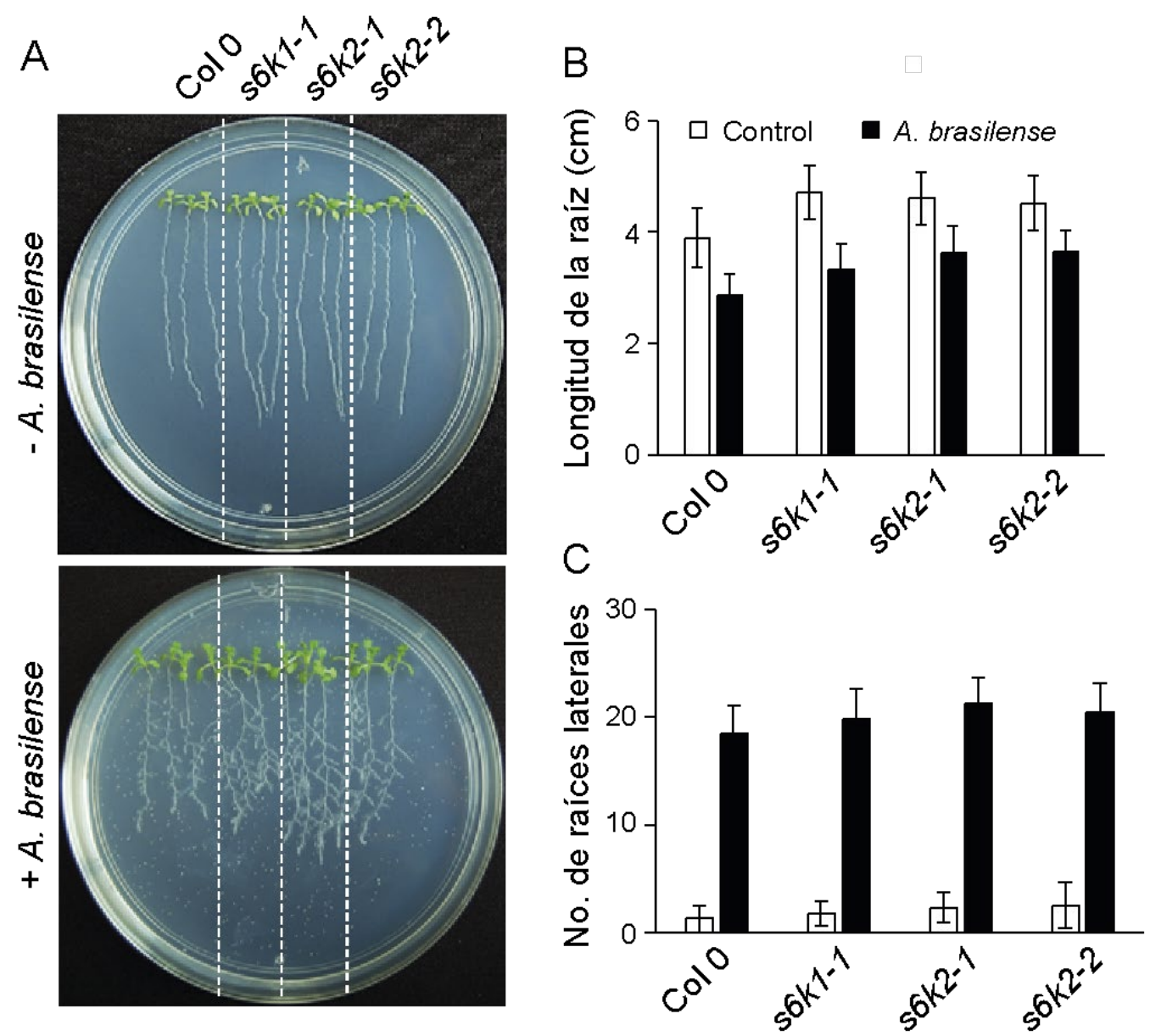

Fig. 5. Efecto de $A$. brasilense sobre mutantes en la proteína S6K. Semillas de $A$. thaliana se germinaron durante 4 días, y después se inocularon con $A$. brasilense. A. Morfología de las plántulas. B, C. Parámetros morfológicos de la raíz. N=30.

Fig. 5. Effect of $A$. brasilense on mutants in the S6K protein. Seeds of $A$. thaliana were germinated during 4 days and then inoculated with $A$. brasilense. A. Morphology of the seedlings. B, C. Morphological parameters of the root. $\mathrm{N}=30$.

\section{DISCUSIÓN}

El género Azospirillum es uno de los más estudiados dentro del grupo de las rizobacterias que promueven el crecimiento vegetal. Se ha reportado que es capaz de colonizar más de cien especies vegetales, mejorando significativamente su crecimiento, desarrollo y productividad bajo condiciones de campo (Bashan \& deBashan, 2010). Sin embargo, se conoce poco sobre los mecanismos moleculares que estimula en la planta para promover el crecimiento celular. La proteína cinasa TOR juega un papel clave en la regulación del crecimiento celular en eucariotes 
(Dobrenel et al., 2016). En este estudio analizamos el papel de ésta proteína durante la interacción de $A$. brasilense con $A$. thaliana.

La inoculación con $A$. brasilense disminuyó el crecimiento de las plántulas y promovió la formación de raíces laterales. El acortamiento de la raíz principal se correlacionó con una disminución en la división celular en el meristemo de la raíz. En contraste, la estimulación de raíces laterales correlacionó con un incremento en la división celular del meristemo. Los resultados observados establecen una relación entre la división celular y los cambios en la morfología de la raíz: a menor división celular el tamaño de la raíz disminuye, y a mayor división celular el tamaño de las raíces laterales se promueve y se incrementa. Esto demuestra que $A$. brasilense regula el crecimiento y la morfología de la raíz a través de su efecto sobre la división celular.

Cuando las plántulas mutantes tor-es se inocularon con $A$. brasilense, en ausencia de estradiol, se observaron efectos morfológicos y de promoción del crecimiento similares a los observados en las plantas silvestres Col0. Sin embargo, cuando se adicionó estradiol al medio, la rizobacteria no promovió el crecimiento observado en ausencia de estradiol. Estos resultados sugieren que el estradiol disminuyó la producción de la proteína TOR, afectando el crecimiento de las plántulas, y que la rizobacteria fue incapaz de recuperar el crecimiento. Si bien en estos experimentos no se analizó el efecto del estradiol sobre la división celular en el meristemo de la raíz, es probable que este afectada porque previamente se demostró que está relacionada con el crecimiento de la raíz. Además, en otro estudio utilizando el inhibidor químico ATP-competitivo de TOR AZD-8055 se observó una disminución en la división celular y en el crecimiento de la raíz (Méndez-Gómez et al., 2020).

Un estudio adicional reporta la importancia de TOR en la regulación del crecimiento vegetal. En este estudio, líneas artificiales de microARN (amiR) de TOR mostraron una severa disminución en el crecimiento. Estas líneas también están condicionadas en la expresión de TOR en Arabidopsis (AtTOR) por la adición de estradiol al medio de crecimiento. Las plantas no solo produjeron menos biomasa, también tuvieron hojas y raíces significativamente más pequeñas. La disminución en la expresión de TOR reveló una fuerte regulación de genes involucrados en el ciclo celular, pared celular y senescencia. También se observaron cambios importantes en metabolitos primarios y secundarios. Este estudio demostró que TOR es un regulador esencial del crecimiento y desarrollo en plantas (Caldana et al., 2013).

En conjunto, los resultados reportados en la literatura y los obtenidos en nuestro estudio, sugieren que la rizobacteria estimula el crecimiento de las plántulas a través de la vía metabólica regulada por la proteína TOR.

En adición, se analizó el efecto de la rizobacteria sobre una de las proteínas blanco de TOR, S6K. Ésta proteína es fosforilada por TOR, y regula a su vez la traducción selectiva de ARNs mensajeros relacionados con la respuesta a hormonas, azúcares, y control del ciclo celular (Kim et al., 2007). Utilizando tres mutantes simples de S6K (s6k1-1, s6k2-1 y s6k2-2), no se observaron diferencias en el crecimiento de las plántulas cuando fueron inoculadas con $A$. brasilense, en relación al control. Esto podría explicarse por la presencia redundante de esta 
proteína, pues existen dos alelos para la misma (S6K1 y S6K2) en Arabidopsis. De esta forma, si una proteína es dañada, su función celular podría ser realizada por la otra proteína. Así, las mutantes simples no permiten obtener información sobre su función durante la interacción de las plántulas con la rizobacteria. Lo anterior sugiere que es necesario realizar estos análisis utilizando mutantes dobles de S6K.

En resumen, los resultados muestran la importancia de la proteína TOR en la regulación del crecimiento de $A$. thaliana durante la interacción con $A$. brasilense.

\section{AGRADECIMIENTOS}

Este estudio fue apoyado por la Coordinación de la Investigación Científica de la Universidad Michoacana de San Nicolás de Hidalgo, y por la beca de doctorado del CONACYT no. 276783, otorgada a MMG.

\section{CONFLICTO DE INTERESES}

Los autores declaran que no existe conflicto de intereses.

\section{REFERENCIAS}

Ardakani M. \& Mafakheri S. 2011. Designing a sustainable agroecosystem for wheat (Triticum aestivum L.) production. Journal of Applied Environmental and Biological Sciences 1:401-413. https://doi.org/10.1016/S1573-5214(07)80001-7.

Bashan Y. \& de-Bashan L.E. 2002. Protection of tomato seedlings against infection by Pseudomonas syringae pv tomato using the plant growth promoting bacterium Azospirillum brasilense. Applied Environmental Microbiology 68:2637-2643. https://doi.org/10.1128/AEM.68.6.2637-2643.2002.

Bashan Y. \& de-Bashan L. E. 2010. How the plant growth-promoting bacterium Azospirillum promotes plant growth. A critical assessment. Advances in Agronomy $108,77 \mathrm{e} 136$.

Bottini R., Fulchieri M., Pearce D. \& Pharis R.P. 1989. Identification of gibberellins A1, A3, and iso-A3 in cultures of Azospirillum lipoferum. Plant Physiology 90:4547. https://doi.org/10.1104/pp.90.1.45.

Burkart G. M. \& Brandizz F. 2021. A Tour of TOR Complex Signaling in Plants. Trends in Biochemical Sciences. 46:417-428.

Caldana C., Li Y., Leisse A., Zhang Y., Bartholomaeus L., Fernie A. R., Willmitzer L. \& Giavalisco P. 2013. Systemic analysis of inducible target of rapamycin mutants reveal a general metabolic switch controlling growth in Arabidopsis thaliana. The Plant Journal. 73:897-909. 
Cohen A.C., Bottini R. \& Piccoli P.N. 2008. Azospirillum brasilense Sp. 245 produces $A B A$ in chemically-defined culture medium and increases ABA content in Arabidopsis plants. Plant Growth Regulation. 54:97-103. https://doi. org/10.1007/s10725-007-9232-9

Creus C.M., Sueldo R.J. \& Barassi C.A. 2004. Water relations and yield in Azospirillum- inoculated wheat exposed to drought in the field. Canadian Journal of Botany. 82:273-281. https://doi.org/10.1139/b03-119.

Creus C., Sueldo R. \& Barassi C. 1997. Shoot growth and water status in Azospirillum inoculated wheat seedlings grown under osmotic and salt stresses. Plant Physiology and Biochemistry. 35, 939e944.

Deprost D., Yao L., Sormani R., Moreau M., Leterreux G., Nicolai, M., et al. 2007. The Arabidopsis TOR kinase links plant growth, yield, stress resistance and mRNA translation. EMBO Reports. 8:864-870. https://doi.org/10.1038/sj.embor.7401043.

Dobrenel T., Caldana C., Hanson J., Robaglia C., Vincentz M., Veit B., et al. 2016. TOR signaling and nutrient sensing. Annual Review of Plant Biology. 67:261- 285. https://doi.org/10.1146/annurev-arplant-043014-114648.

Jha C.K. \& Saraf M. 2015. Plant growth promoting rhizobacteria (PGPR): a review. Journal of Agricultural Research and Development. 5:0108-0119.

Khan M.R., Kounsar K. \& Hamid A. 2002. Effect of certain rhizobacteria and antoagonistic fungi on root-nodulation and root-knot nematode disease of green gram. Nematologia Mediterranea 30:85-89.

Khan N. \& Bano A. 2016. Modulation of phytoremediation and plant growth by the treatment of PGPR, Ag nanoaprticle and untreated municipal wastewater 6514. https://doi.org/10.1080/15226514.2016.1203287.

Kim Y-C., Glick B.R., Bashan Y. \& Ryu C-M. 2012. Enhancement of plant drought tolerance by microbes. In: Aroca R (ed) Plant responses to drought stress: from morphological to molecular features. Springer Verlag, Berlin, pp 383-413. ISBN 978-3-642-32653-0.

Kim B.H., Cai X., Vaughn J.N. \& von Arnim A.G. 2007. On the functions of the $h$ subunit of eukaryotic initiation factor 3 in late stages of translation initiation. Genome Biology. 8: R60.

Malamy, J.E. \& Benfey, P.N. 1997. Organization and cell differentiation in lateral roots of Arabidopsis thaliana. Development, 124, 33-44 
Menand, B., Desnos, T., Nussaume, L., Berger, F., Bouchez, D., Meyer, C. \& Robaglia C. 2002. Expression and disruption of the Arabidopsis TOR (target of rapamycin) gene. Proc. Natl. Acad. Sci. U. S. A 99, 6422-6427. https://doi.org/ 10.1073/ pnas.092141899

Mendez-Gomez M., Castro-Mercado E., Peña-Uribe C.A., Reyes-de la Cruz H., Lopez-Bucio J. \& Garcia-Pineda E. 2020.TARGET OF RAPAMYCIN signaling plays a role in Arabidopsis growth promotion by Azospirillum brasilense Sp245. Plant Science. 293: 110416. https://doi.org/10.1016/j.plantsci.2020.110416.

Murashige T. \& Skoog F. 1962. A revised medium for rapid growth and bio assays with tobacco tissue cultures. Physiologia Plantarum. 15: 473-497.

Puente M., Li C. \& Bashan Y. 2004. Microbial populations and activities in the rhizoplane of rock-weathering desert plants. II. Growth promotion of cactus seedlings. Plant Biology. 6: 643e650.

Romero A.M., Correa O.S., Moccia S. \& Rivas J.G. 2003. Effect of Azospirillummediated plant growth promotion on the development of bacterial diseases on fresh-market and cherry tomato. Journal of Applied Microbiology. 95: 832-838. https://doi.org/10.1046/j.1365-2672.2003.02053.x.

Sahoo R.K., Ansari M.W., Pradhan M., Dangar T.K., Mohanty S. \& Tuteja N. 2014. Phenotypic and molecular characterization of native Azospirillum strains from rice fields to improve crop productivity. Protoplasma. 251: 943-953. https://doi.org/10.1007/s00709-013-0607-7.

Shi L., Wu Y. \& Sheen J. 2018. TOR signaling in plants: conservation and innovation. Development. 145, dev160887. https://doi.org/ 10.1242/dev.160887.

Spaepen S., Bossuyt S., Engelen K., Marchal K. \& Vanderleyden J. 2014. Phenotypical and molecular responses of Arabidopsis thaliana roots as a result of inoculation with the auxin-producing bacterium Azospirillum brasilense. New Phytologist. 201:850-861. https://doi.org/10.1111/nph.12590

Spaepen S. \& Vanderleyden J. 2015. Auxin signaling in Azospirillum brasilense: a proteome analysis. In: de Bruijn FJ (ed) Biological nitrogen fixation. Wiley, Hoboken, pp 937-940. https://doi.org/10.1002/9781119053095.ch91.

Strzelczyk E., Kampert M. \& Li C.Y. 1994. Cytokinin-like substances and ethylene production by Azospirillum in media with different carbon sources. Microbiological Research.149: 55-60. https://doi.org/10.1016/ S0944-5013(11)80136-9.

Sudha G. \& Ravishankar G.A. 2002. Involment and interaction of various signaling compounds on the plant metabolic events during defense response, resistance to stress factors, formation of secondary metabolites and their molecular aspects. 
Plant Cell and Tissue Organ Culture 71: 181-212. https://doi.org/10.1023/A:1020336626361.

Tabassum B., Khan A., Tariq M., Ramzan M., Saleem M., Khan I., Shahid N. \& Aaliya K. 2017. Bottlenecks in commercialisation and future prospects of PGPR. Applied Soil Ecology.121, 102e117. https://doi.org/10.1016/j.apsoil.2017.09.030.

Thijs S., Sillen W., Rineau F., Weyens N. \& Vangronsveld J. 2016. Towards an enhanced understanding of plantemicrobiome interactions to improve phytoremediation. Engineering the Metaorganism 7, 1e15. https://doi.org/10.3389/ fmicb.2016.00341.

Tien T.M., Gaskins M.H. \& Hubbell D.H. 1979. Plant growth substances produced by Azospirillum brasilense and their effect on the growth of Pearl Millet (Pennisetum americanum L.). Applied Environmental Microbiology. 37: 1016-1024.

Tiwari S., Lata C., Chauhan P.S. \& Nautiyal C.S. 2015. SC. Plant Physiology Biochemistry. 99, 108e117. https://doi.org/10.1016/j.plaphy.2015.11.001.

Tortora M.L., Díaz-Ricci J.C. \& Pedraza R.O. 2011. Azospirillum brasilense siderophores with antifungal activity against Colletotrichum acutatum. Archives of Microbiology.193: 275-286. https://doi.org/10.1007/s00203-010-0672-7.

Turan M., Gulluce M., von Wirén N. \& Sahin F. 2012. Yield promotion and phosphorus solubilization by plant growth-promoting rhizobacteria in extensive wheat production in Turkey. Journal of Plant Nutrition and Soil Science.175: 818826. https://doi.org/10.1002/jpln.201200054.

van Loon L.C. \& Bakker P. 2005. Induced systemic resistance as a mechanism of disease suppression by rhizobacteria. In: PGPR: Biocontrol and biofertilization. The Netherlands: Springer, pp 39-66. https://doi.org/10.1007/1-4020-4152-7_2.

Vishan I., Saha B., Sivaprakasam S. \& Kalamdhad A. 2019. Evaluation of Cd(II) biosorption in aqueous solution by using lyophilized biomass of novel bacterial strain Bacillus badius AK: biosorption kinetics, thermodynamics and mechanism. Environmental Technology Innovation. 100323 https://doi.org/10.1016/j.eti.2019.100323.

Xiong Y., McCormack M., Li L., Hall Q., Xiang C. \& Sheen J. 2013. Glucose-TOR signalling reprograms the transcriptome and activates meristems. Nature. $2013 \mathrm{Apr}$ 11;496(7444):181-6. doi: 10.1038/nature12030. Epub. PMID: 23542588; PMCID: PMC4140196.

Xiong Y. \& Sheen J. (2012). Rapamycin and Glucose-Target of Rapamycin (TOR) protein signaling in plants. Journal of Biological Chemistry. 287, 2836-2842. https://doi.org/ 10.1074/ jbc.M111.300749. 
Xiong Y. \& Sheen J. 2014. The role of target of rapamycin signaling networks in plant growth and metabolism. Plant Physiology.164: 499-512. https://doi.org/ 10.1104/ pp.113.229948.

Zhou D. \& Huang X. 2015. Root and bacterial secretions regulate the interaction between plants and PGPR leading to distinct plant growth promotion effects. https://doi.org/10.1007/s11104-015-2743-7.

Zoncu R., Bar-Peled L., Efeyan A., Wang S., Sancak Y. \& Sabatini D. M. 2011. mTORC1 senses lysosomal amino acids through an inside-out mechanism that

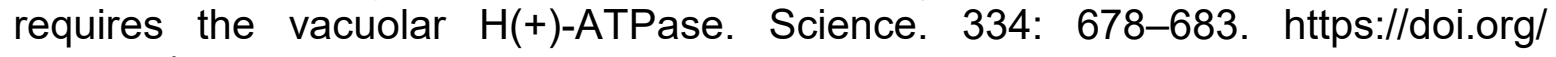
10.1126/science.1207056. 